\title{
Phenotypic and Molecular Cytogenetic Analysis of a Case of Monosomy 1 p36 Syndrome due to Unbalanced Translocation
}

\author{
Dalia F. Hussen ${ }^{\mathrm{a}} \quad$ Alaa K. Kamel ${ }^{\mathrm{a}} \quad$ Mona K. Mekkawy $^{\mathrm{a}}$ Engy A. Ashaat ${ }^{\mathrm{b}}$ \\ Mona O. El Ruby \\ ${ }^{a}$ Human Cytogenetics Department, National Research Centre, Cairo, Egypt; ${ }^{b}$ Clinical Genetics Department, National \\ Research Centre, Cairo, Egypt
}

\section{Keywords}

Chromosomal microarray · FISH · Haploinsufficiency ·

Monosomy 1 p36 syndrome - Unbalanced translocation

\begin{abstract}
Monosomy $1 \mathrm{p} 36$ syndrome is one of the most common submicroscopic deletion syndromes, which is characterized by the presence of delayed developmental milestones, intellectual disability, and clinically recognizable dysmorphic craniofacial features. The syndrome comprises 4 cytogenetic groups including pure terminal deletions, interstitial deletions, complex rearrangements, and derivative chromosomes 1 due to unbalanced translocations, where unbalanced translocations represent the least percentage of all cases of monosomy 1 p36 (7\%). Most patients with monosomy $1 \mathrm{p} 36$ due to an unbalanced translocation can be cytogenetically diagnosed using conventional techniques. However, chromosomal microarray analysis is mandatory in these cases to detect copy number variance and size of the deletion and allows for setting a phenotype-genotype correlation. Here, we studied a 1.5-year-old female patient who showed intellectual disability, delayed milestones, hypotonia, seizures, and characteristic dysmorphic features including brachycephaly, straight eyebrows, deep-set eyes, downslanting palpebral fissures, midface hypoplasia, de-
\end{abstract}

pressed nasal bridge, long philtrum, and pointed chin. Conventional cytogenetic analysis (CCA), microarray study, and fluorescence in situ hybridization (FISH) analysis were performed. CCA showed a translocation involving chromosomes 1 and 21, 45,XX, der(1)t(1;21)(p36.32;q21.1)dn. Microarray analysis revealed copy number losses at both $1 \mathrm{p} 36$ and proximal 21q. FISH confirmed the presence of the $1 \mathrm{p} 36$ deletion, but was not performed for $21 \mathrm{q}$. We have concluded that phenotype-genotype correlation for monosomy 1 p36 syndrome can be performed for the fundamental clinical manifestations; however, the final aspect of the syndrome depends on composite factors. Monosomy 1 p36 due to unbalanced translocation may present either classically or with additional altered features of various severity based on the copy number variations involving different chromosomes.

(c) 2020 S. Karger AG, Basel

\section{Introduction}

Submicroscopic deletion syndromes involve syndromes with deletions that can barely be detected by conventional cytogenetic techniques. Monosomy 1p36 syndrome (OMIM \#607872) is considered one of the most common submicroscopic deletion syndromes with an estimated prevalence of 1:5,000 births [Shaffer and Lupski, 
2000; Battaglia et al., 2008]. It is also thought to be the most common terminal deletion syndrome [Heilstedt et al., 2003a,b].

Delayed developmental milestones, intellectual disability, and distinguished dysmorphic craniofacial features are the cardinal presentations of this syndrome. The characteristic dysmorphic features include straight eyebrows, deeply set eyes, low-set ears, midface hypoplasia, depressed nasal bridge, long philtrum, and pointed chin. Other important findings include anatomical brain anomalies, hypotonia, seizures, poor or absent speech, congenital heart diseases, as well as microbrachycephaly. Skeletal anomalies, visual problems, hearing loss, abnormalities of the external genitalia, and renal abnormalities have also been reported in some patients with this syndrome [Shapira et al., 1997; Battaglia et al., 2008; Shimada et al., 2015].

The condition arises as a de novo abnormality in about $52 \%$ of cases [Battaglia et al., 2008]. The deletion size of monosomy 1 p36 syndrome encompasses a wide range starting from about $1.5 \mathrm{Mb}$ up to more than $10 \mathrm{Mb}$ with no common breakpoint [Ballif et al., 2003]. However, breakpoints are most commonly located in the region between 1p36.13 and 1p36.33 [Firth et al., 2009].

Four cytogenetic groups of this syndrome have been previously described, including pure terminal deletions, interstitial deletions, complex rearrangements, and derivative chromosomes 1 from unbalanced translocations.

Cases with pure terminal deletions represent the vast majority. Complex rearrangements including terminal deletions with inverted duplications, large duplications, triplications or more than one interstitial deletion may occur in approximately one third of the patients [Gajecka et al., 2007]. On the other hand, derivative chromosomes 1 as a result of unbalanced translocations represent the least percentage of all cases of monosomy 1p36 (7\%) [Battaglia et al., 2008], occurring either de novo or as a consequence of malsegregation of a balanced parental translocation [Firth et al., 2009].

Although cases with unbalanced translocation can be certainly diagnosed using G-banding, chromosomal microarray analysis is crucial to detect copy number variance, size of the deletion, and to allow for the identification of candidate genes for specific features of the syndrome and for proper phenotype-genotype correlation [Temtamy et al., 2011; Watanabe et al., 2016].

In this study, we report on the clinical features and molecular cytogenetic results in a case of monosomy 1 p36 due to unbalanced translocation, in an attempt to trace the phenotypic variability in deletions resulting from derivative chromosome 1 . We also tried to determine any genotype-phenotype correlation to study the importance of genes involved in the causation of the phenotypic abnormalities in cases of monosomy 1 p36 due to unbalanced translocation.

\section{Patient and Methods}

\section{Clinical Report}

The proband of this study is a female infant. She was 18 months old when referred for the first time to the Multiple Congenital Anomalies Clinic, Centre of Excellence for Human Genetics, National Research Centre. The parents' main concerns were that their child had global developmental delay (mental and motor), hypotonia, seizures, congenital heart disease, and squint. The girl is the first and only child of nonconsanguineous apparently healthy parents. The pregnancy history was uneventful, with no specific remarkable family history of seizure, delayed development, hypotonia, or language delay. However, there is a history of affected family members with congenital heart disease. She had normal birth weight $(3 \mathrm{~kg})$ as mentioned by the parents.

General clinical examination revealed intellectual disability, delayed motor and mental milestones in the form of delayed walking, hypotonia, and absent speech. She was dysmorphic, showed facial features including brachycephaly, low anterior and posterior hairlines, hypotonic face, midface hypoplasia, straight eyebrows, deep-set eyes, strabismus, hypotelorism, downslanting palpebral fissures, low-set posteriorly rotated ears, prominent broad forehead, flat broad nose with downward columella, long philtrum, microstomia, pointed chin, short neck, skeletal abnormalities in the form of bilateral broad big toes, characteristic small feet, brachydactyly with talipes and bilateral broad thumbs. She had generalized hirsutism.

Anthropometric measurements were all on mean for age; her weight was $9.5 \mathrm{~kg}$, length was $78 \mathrm{~cm}$, and head circumference was $45 \mathrm{~cm}$.

Neurological examination showed hypotonia, hyporeflexia, and inability to stand unsupported. Brain MRI revealed delayed white matter myelination related to age and minimal brain subvolume.

Cardiac evaluation was performed by echocardiography and revealed atrial septal defect (ASD) and patent ductus arteriosus (PDA).

Pelvic-abdominal ultrasound and hearing test were normal. Complete eye and fundus examination revealed squint, myopia, and astigmatism. Thyroid function test was done and showed hypothyroidism. Follow-up at the age of 3 years revealed short stature for her age, but her weight and head circumference were appropriate for her age. The patient still showed severe global developmental delay and intellectual disability, remarkable hypotonia, and she could not walk unsupported. She regularly attended physiotherapy sessions. Dysmorphic features had became more obvious, her vision had deteriorated with severe myopia $(-6)$ and aggravated strabismus. Speech and language development were severely delayed. She even could not speak few words. She is undergoing speech and cognitive therapy. 


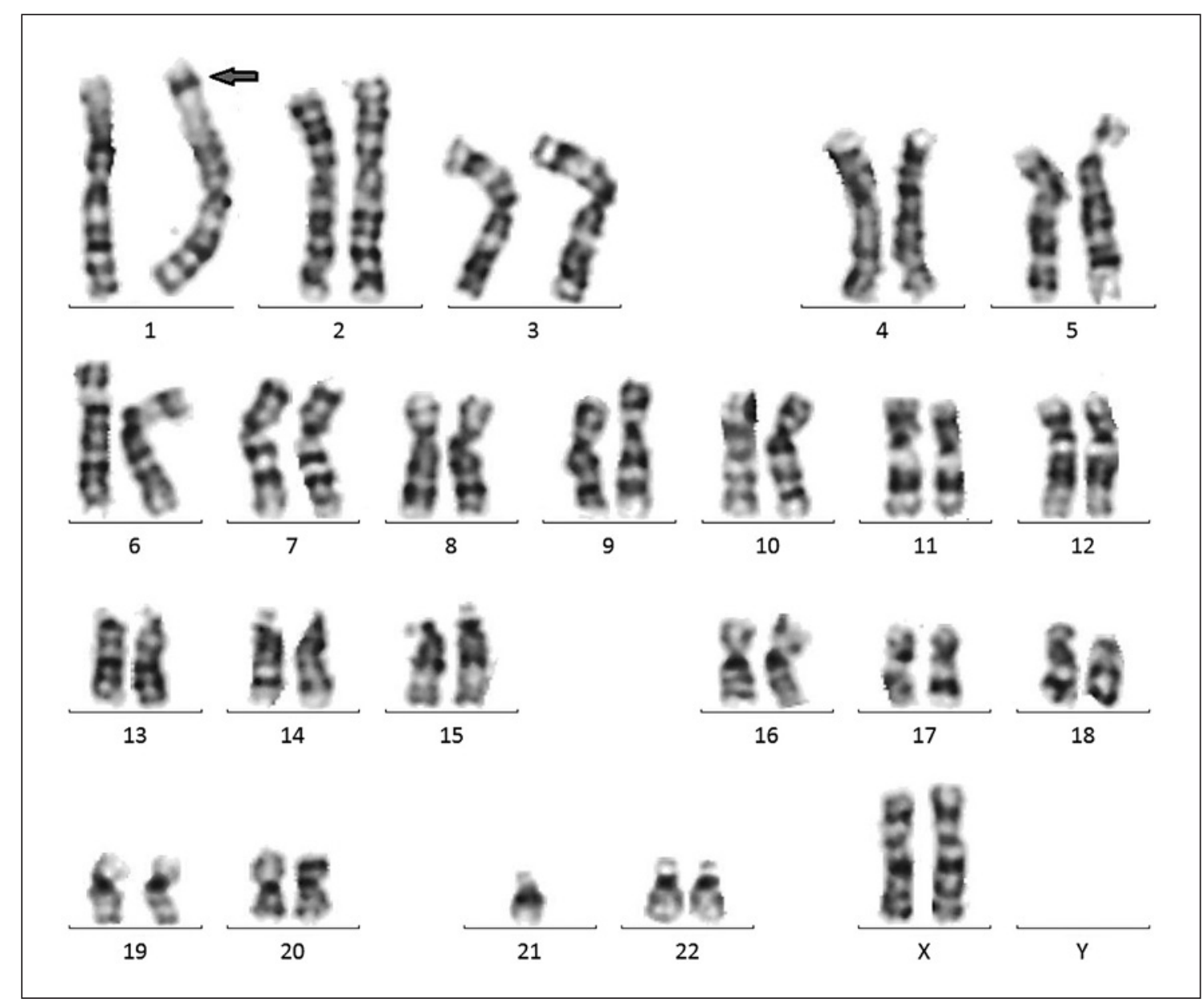

Fig. 1. Karyotype of the proband showing 45,XX, $\operatorname{der}(1) \mathrm{t}(1 ; 21)(\mathrm{p} 36.32 ; \mathrm{q} 21.1) \mathrm{dn}$.

Cytogenetic Studies

Conventional cytogenetic analysis (CCA) of peripheral blood chromosomes was performed for the family trio to detect any numerical or structural chromosomal aberrations using the GTG banding technique [Verma and Babu, 1995]. Approximately 30 metaphases were analyzed and karyotyped for each of them, and cytogenetic nomenclature followed the International System for Human Cytogenomic Nomenclature [ISCN, 2016] recommendations.

Chromosomal microrray analysis was performed for the patient to detect submicroscopic copy number changes using the BlueGnome CytoChip ISCA $8 \times 60 \mathrm{~K}$ v2.0 array as well as a genome-wide resolution of $500 \mathrm{~kb}$ using BlueFuse Multi 2.6 Software (Build 37).

FISH was done for the proband to confirm the presence of the 1 p36 deletion as well as detecting the chromosomal breakpoints. The technique was carried out according to modifications of Pinkel et al. [1986]. The SKI probe is $115 \mathrm{~kb}$, labeled in red and covers a region including most of the SKI gene, the telomeric end of the MORN1 gene, and the D1S2515 marker (Cytocell FISH probes; Oxford Gene Technology, Cambridge, UK). DAPI II (4',6-diamid- ino-2-phenylindole dihydrochloride) was used as a counterstain. At least 100 cells were analyzed with a Zeiss Axioplan Microscope (Zeiss, Le Pecq, France). Image acquisition was performed using a CCD camera and analyzed using the ISIS program (In Situ Imaging System, MetaSystems, Altlussheim, Germany).

\section{Results}

CCA for the parents revealed normal karyotypes, 46,XX and 46,XY for the mother and the father, respectively. In the proband, however, all cells showed 45,XX,der(1)t(1;21)(p36.32;q21.1)dn (Fig. 1).

Microarray study revealed a terminal copy number loss of approximately 2.4 Mb in 1p36.33 to p36.32 (Fig. 2) and a copy number loss of about $1.8 \mathrm{Mb}$ in proximal 21q11.2toq21.1:arr[hg19]1p36.33p36.32(779727_3161082) $\times 1,21 q 11.2 q 21.1\left(15485008 \_17360796\right) \times 1$ 


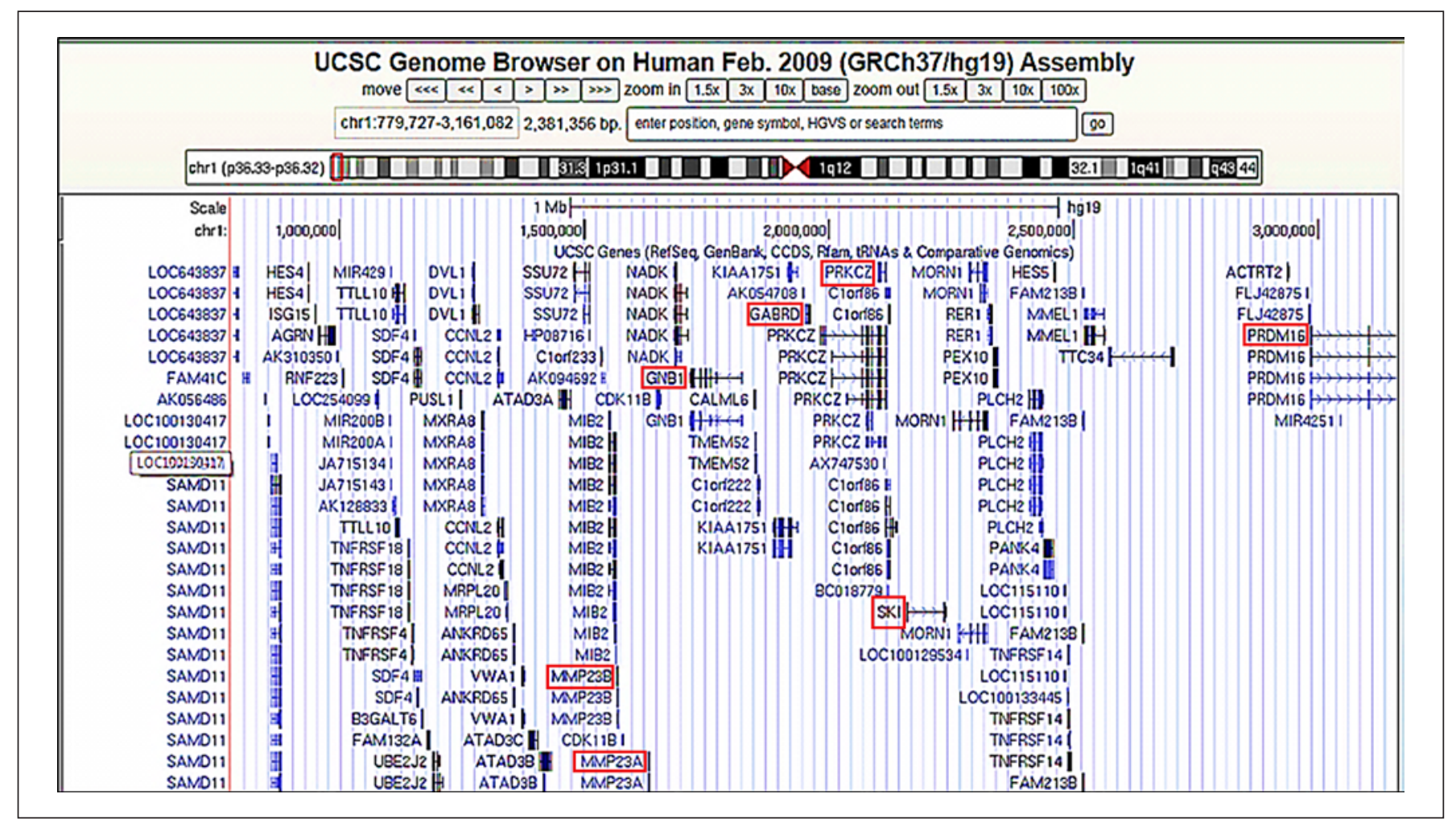

Fig. 2. Microarray analysis revealed the deleted region of 1 p36 (1p36.33-p36.32) with all affected genes. The clinically relevant genes are framed in red.

FISH analysis revealed $\operatorname{del}(1)(\mathrm{p} 36)$ (Fig. 3), but this technique was not performed for proximal 21q.

\section{Discussion}

In the current study, we report on a female patient who presented with clinical features suggestive of monosomy 1 p36 syndrome.

Patients with monosomy 1 p36 syndrome previously described by Shapira et al. [1997], Heilstedt et al. [2003b], and Battaglia et al. [2008] showed distinctive craniofacial features, intellectual disability, and developmental delay with variable degrees of severity.

Typical craniofacial features of monosomy 1p36 syndrome include microcephaly and/or brachycephaly, large, late-closing anterior fontanel, straight eyebrows, deep-set eyes, midface hypoplasia, broad nasal bridge, long philtrum, pointed chin, and low-set ears [Battaglia et al., 2008].

Generally, Bahi-Buisson et al. [2008] and Battaglia et al. [2008] rated dysmorphic features, intellectual disabil-

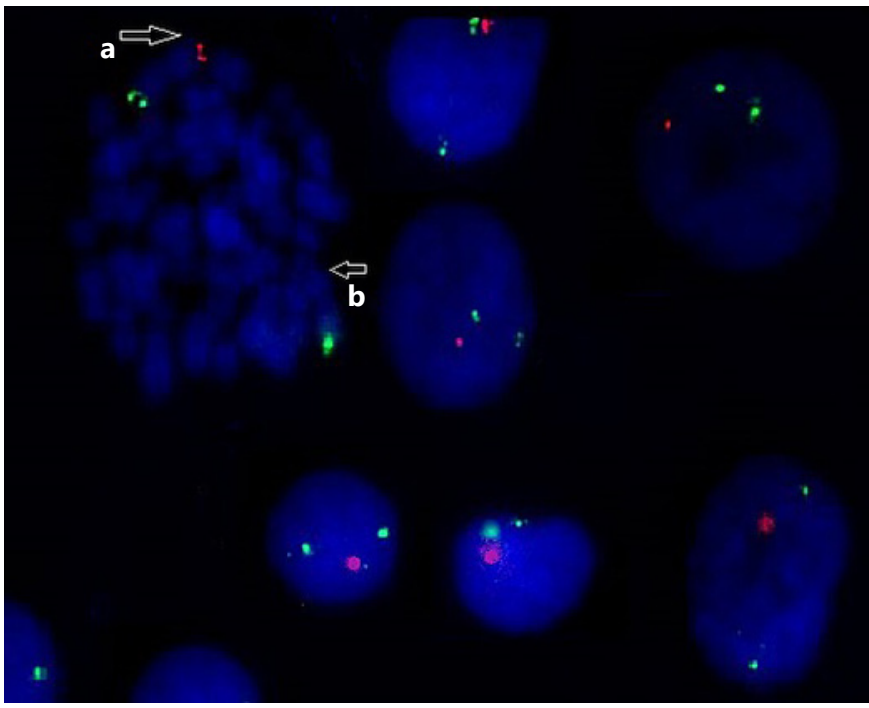

Fig. 3. Metaphase and interphase FISH showing del(1)(p36). Arrow (a) points to the red signal indicating a normal chromosome 1 in the metaphase, arrow (b) points to the deleted chromosome 1 indicated by the absence of the red signal. 
Table 1. Cardinal features of our patient compared to those previously detected in patients with monosomy 1 p36

\begin{tabular}{|c|c|c|c|}
\hline Clinical findings & $\begin{array}{l}\text { Frequency of findings in patients } \\
\text { reported by Rosenfeld et al. [2010] }\end{array}$ & $\begin{array}{l}\text { Frequency of findings in patients } \\
\text { reported by Shimada et al. [2015] }\end{array}$ & $\begin{array}{l}\text { Findings in } \\
\text { our patient }\end{array}$ \\
\hline \multicolumn{4}{|l|}{ Dysmorphic features } \\
\hline Microcephaly & $63 \%$ & $83 \%$ & - \\
\hline Brachycephaly & NA & $65 \%$ & + \\
\hline Large or late-closing anterior fontanel & $75 \%$ large anterior fontanel & $56 \%$ late-closing anterior fontanel & - \\
\hline Midface hypoplasia & $80 \%$ & NA & + \\
\hline Straight eyebrows & $100 \%$ & $84 \%$ & + \\
\hline Deep-set eyes & $88 \%$ & $93 \%$ & + \\
\hline Low-set ears & $40 \%$ & $88 \%$ & + \\
\hline Broad nasal bridge & $88 \%$ & $57 \%$ & + \\
\hline Long philtrum & NA & $88 \%$ & + \\
\hline Pointed chin & $84 \%$ & $89 \%$ & + \\
\hline \multicolumn{4}{|l|}{ Developmental findings } \\
\hline Intellectual disability & $98 \%$ & $98 \%$ & + \\
\hline Developmental delay & $100 \%$ & $68 \%$ did not acquire independent gait & + \\
\hline \multicolumn{4}{|l|}{ Neurological findings } \\
\hline Hypotonia & $94 \%$ & $92 \%$ & + \\
\hline Seizures & $60 \%$ & $70 \%$ & + \\
\hline \multicolumn{4}{|l|}{ Cardiac abnormalities } \\
\hline \multirow[t]{2}{*}{ Structural cardiac defects } & $0 \%$ & PDA $37 \%$ & + \\
\hline & & ASD $16 \%$ & \\
\hline Cardiomyopathy & $0 \%$ & NA & - \\
\hline
\end{tabular}

ASD, atrial septal defect; NA, not applicable; PDA, patent ductus arteriosus; +, positive finding; -, negative finding.

ity, developmental delay, delayed or absent speech, and hypotonia as the cardinal features of monosomy $1 \mathrm{p} 36$ with a collective percentage of more than $75 \%$ of the patients. Subsequent important clinical data include seizures and cardiac abnormalities with a percentage of 50$75 \%$, followed by other less frequent findings, e.g., skeletal abnormalities, sensorineural deafness, gastrointestinal anomalies, and hypothyroidism.

All craniofacial features reported in our study are in conformity to those described by Battaglia et al. [2008] apart from large, late-closing anterior fontanel. Dysmorphic features observed in our patient were also comparable to the studies done by Rosenfeld et al. [2010] and Shimada et al. [2015] (Table 1).

Intellectual disability and developmental delay, present in our patient, are principle findings in patients with monosomy $1 \mathrm{p} 36$.

Our patient also manifested generalized hypotonia which is a prevailing feature reported in $92-95 \%$ of those patients [Battaglia et al., 2008; Rosenfeld et al., 2010; Shimada et al., 2015]. Corresponding to multiple previous studies [Zaveri et al., 2014; Shimada et al., 2015], seizures and cardiac abnormalities in the form of ASD and PDA were observed in our patient. Different cardiac abnormalities including both cardiomyopathy and structural cardiac defects have been described in patients with 1 p36 deletion [Gajecka et al., 2007].

Skeletal abnormalities have been identified in about $41 \%$ of monosomy 1 p36 patients including clinodactyly, vertebral scoliosis, rib abnormalities, and asymmetry in lower limbs [Shapira et al., 1997; Battaglia et al., 2008]. Our patient revealed skeletal abnormality in the form of bilateral short feet, brachydactyly, mild talipes, and bilateral broad thumbs and toes. However, her father has the same broad thumb which could be a familial finding.

During the investigations our patient revealed hypothyroidism, which has been reported in about $15-20 \%$ of patients with this syndrome [Heilstedt et al., 2003b; Battaglia et al., 2008]. Brain MRI showed defective white matter myelination for age in our proband. This finding is consistent with Vigdorovich et al. [2020] who emphasized that micro-rearrangement syndromes including 1 p36 deletion syndrome should be considered in patients with delayed myelination or hypomyelination of white matter. 
Table 2. Deleted genes in our patient that may contribute to monosomy 1 p36 phenotype

\begin{tabular}{|c|c|c|}
\hline Deleted genes in our patient & Previously described phenotype due to haploinsufficiency & References \\
\hline SKI (OMIM *164780) & $\begin{array}{l}\text { Developmental delay, intellectual disability, seizures, dysmorphic features, } \\
\text { congenital heart defects and hypotonia }\end{array}$ & $\begin{array}{l}\text { Rosenfeld et al. [2010] } \\
\text { Jordan et al. [2015] }\end{array}$ \\
\hline$G A B R D\left(O M I M{ }^{\star} 137163\right)$ & Epilepsy and neurodevelopmental abnormalities & Jordan et al. [2015] \\
\hline GNB1 $(\mathrm{OMIM} * 139380)$ & Intellectual disability & Rosenfeld et al. [2010] \\
\hline $\begin{array}{l}\text { MMP23A }\left(\mathrm{OMIM}{ }^{\star} 603320\right) \\
M M P 23 B\left(\mathrm{OMIM}{ }^{*} 603321\right)\end{array}$ & Large, late-closing anterior fontanel & $\begin{array}{l}\text { Gajecka et al. [2005] } \\
\text { Jordan et al. [2015] }\end{array}$ \\
\hline \multirow[t]{2}{*}{ PRDM16 (OMIM *605557) } & Positive for cardiomyopathy & Arndt et al. [2013] \\
\hline & Negative for cardiomyopathy & De Leeuw and Houge [2014] \\
\hline
\end{tabular}

Although monosomy 1p36 is a clinically recognizable syndrome, phenotypic differences are frequently detected between patients. These may be attributed to the genetic variability which includes terminal and interstitial deletions of varying positions [Jordan et al., 2015]. Anal$y$ sis of the genetic content of these deletions allows detecting the candidate genes for certain clinical manifestations [Rosenfeld et al., 2010]. Chromosomal microarray analysis is thus mandatory to identify genes located in the deleted region for each individual case [Jordan et al., 2015].

Throughout our study, CCA for the patient showed an unbalanced translocation between chromosome 1 and chromosome 21 while the parental karyotypes were normal. Chromosomal microrray analysis revealed an approximately $2.4-\mathrm{Mb}$ terminal loss of chromosome 1 , representing bands $1 \mathrm{p} 36.33$ to $1 \mathrm{p} 36.32$ and a deletion in chromosome 21 of about $1.8 \mathrm{Mb}$ comprising bands 21q11.2 to 21q21.1. FISH analysis confirmed the presence of the $1 \mathrm{p} 36$ deletion.

Our patient shows haploinsufficiency of multiple genes within the deleted region of chromosome 1 (Fig. 2), the clinically most relevant ones being SKI (OMIM *164780), GABRD (OMIM *137163), GNB1 (OMIM *139380), PRKCZ (OMIM *176982), MMP23B (OMIM *603321), MMP23A (OMIM * 603320), and PRDM16 (OMIM *605557) (Table 2).

Haploinsufficiency of both SKI and GNB1 genes has frequently been described with monosomy 1p36 syndrome. SKI has been linked to facial dysmorphic features, delayed developmental milestones as well as hypotonia, while GNB1 was associated with intellectual disability [Seo et al., 2016]. Accordingly, haploinsufficiency of both genes in our patient could be consistently correlated with the clinical findings.

Monosomy 1p36 Syndrome due to Unbalanced Translocation
$G A B R D$ encodes a subunit for gamma-aminobutyric acid, i.e., the fundamental inhibitory neurotransmitter in the brain. Consequently, haploinsufficiency of GABRD may be implicated in the neurological phenotype, mainly seizures [Windpassinger et al., 2002].

$P R K C Z$ may be another gene contributing to the neurological manifestations as it encodes protein kinase C-zeta which is considered crucial for facilitating axon differentiation [Zhang et al., 2007]. Thus, it is necessary for proper brain development and function [Rosenfeld et al., 2010]. Haploinsufficiency of $P R K C Z$ in our patient could augment the neurological phenotype-genotype association.

According to Gajecka et al. [2005], defects in MMP23A and/or $M M P 23 B$ have been proposed to cause large, lateclosing anterior fontanels. Although these genes are located within the deleted region of our patient, their deletion did not show an influence on the patient's phenotype, as she presented with closed anterior fontanel at the age of 1.5 years. Shimada et al. [2015] clarified that haploinsufficiency of a gene and its corresponding phenotype cannot be generally verified, and the altered expression of a few genes close to the deleted segments could also be involved in the phenotypic variability. It has also been proposed that a positional effect on one or more genes along the locus of 1 p36 rather than typical contiguous gene deletion can modify the classical phenotype [Seo et al., 2016].

PRDM16 haploinsufficiency has been reported in association with cardiomyopathy [Arndt et al., 2013]. This association is contradictory to our data that revealed only structural cardiac abnormality in the form of ASD and PDA. De Leeuw and Houge [2014] mentioned that multiple deletions of PRDM16 are recorded in the Database 


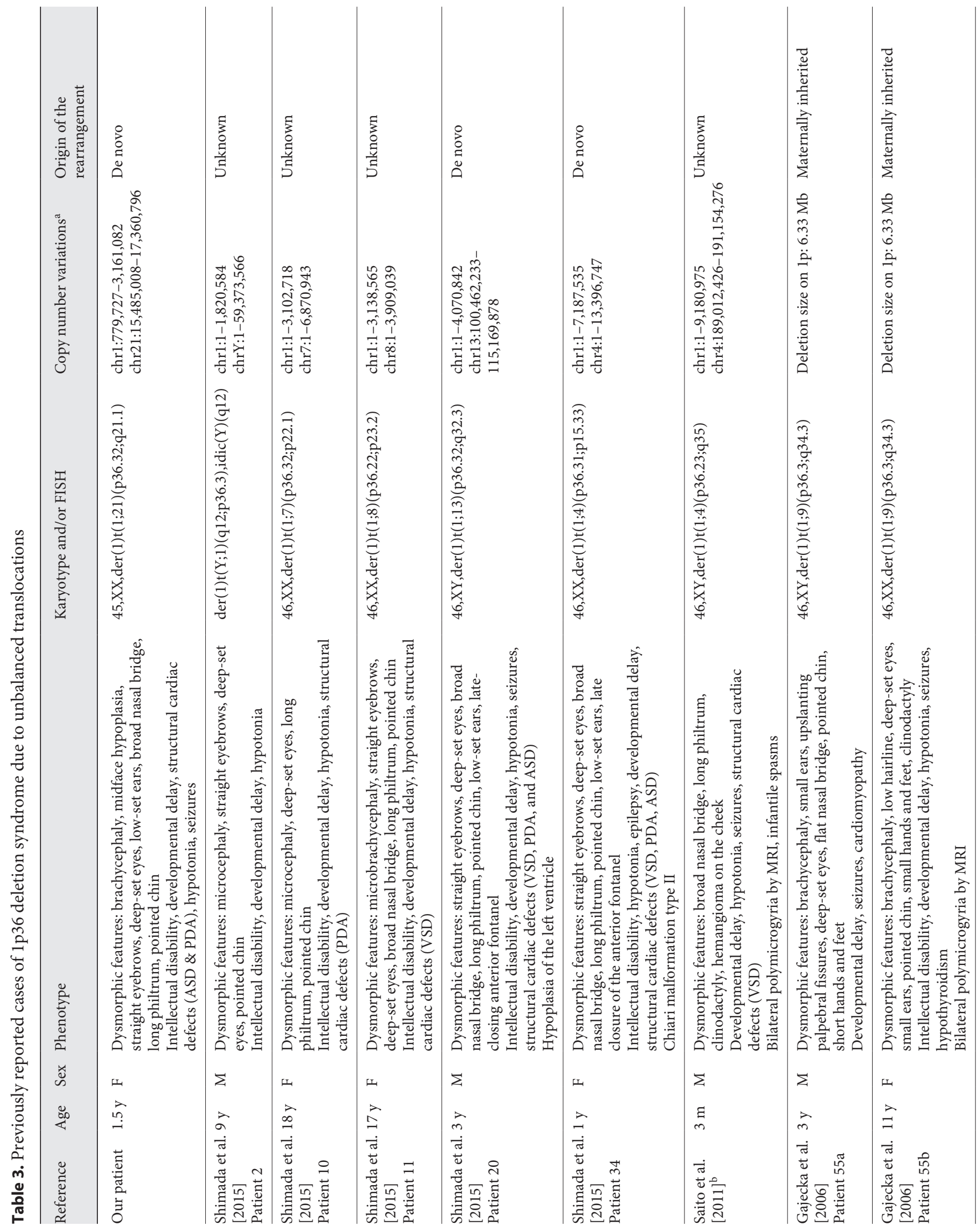




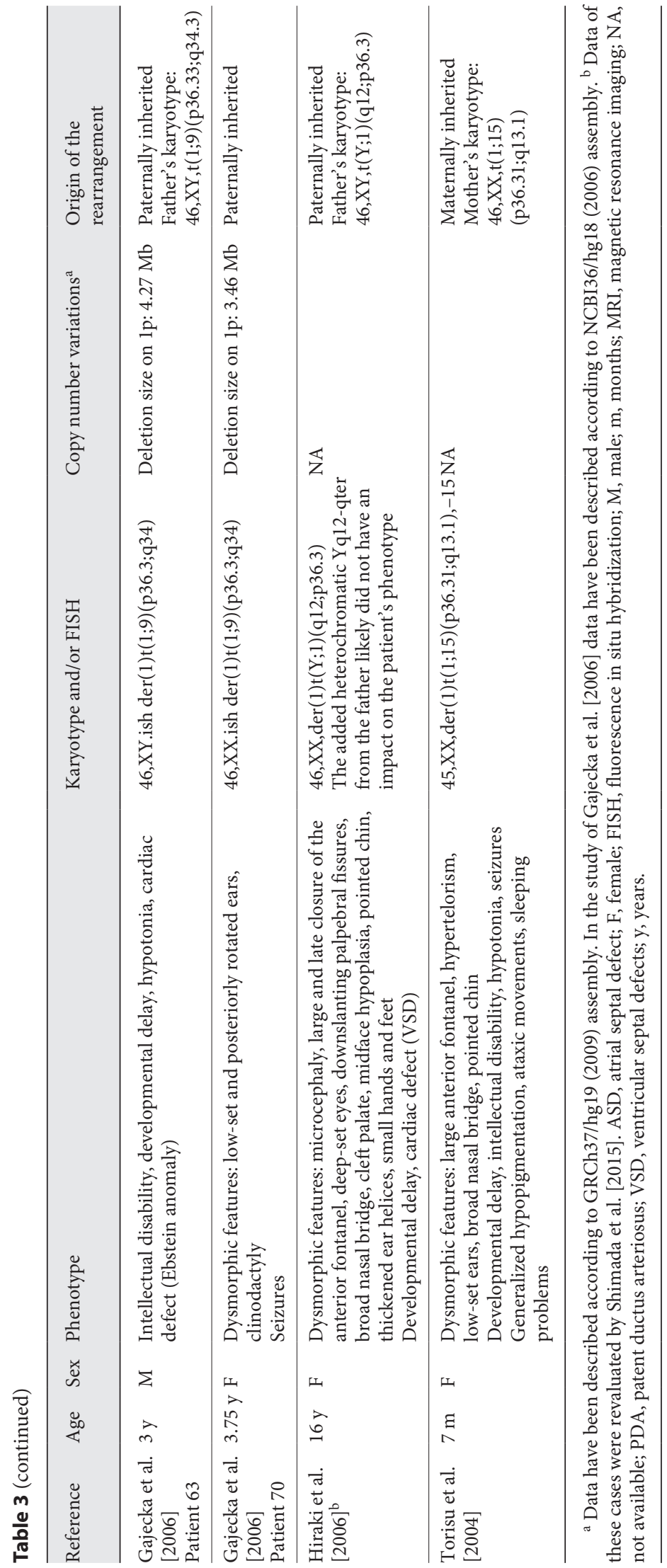




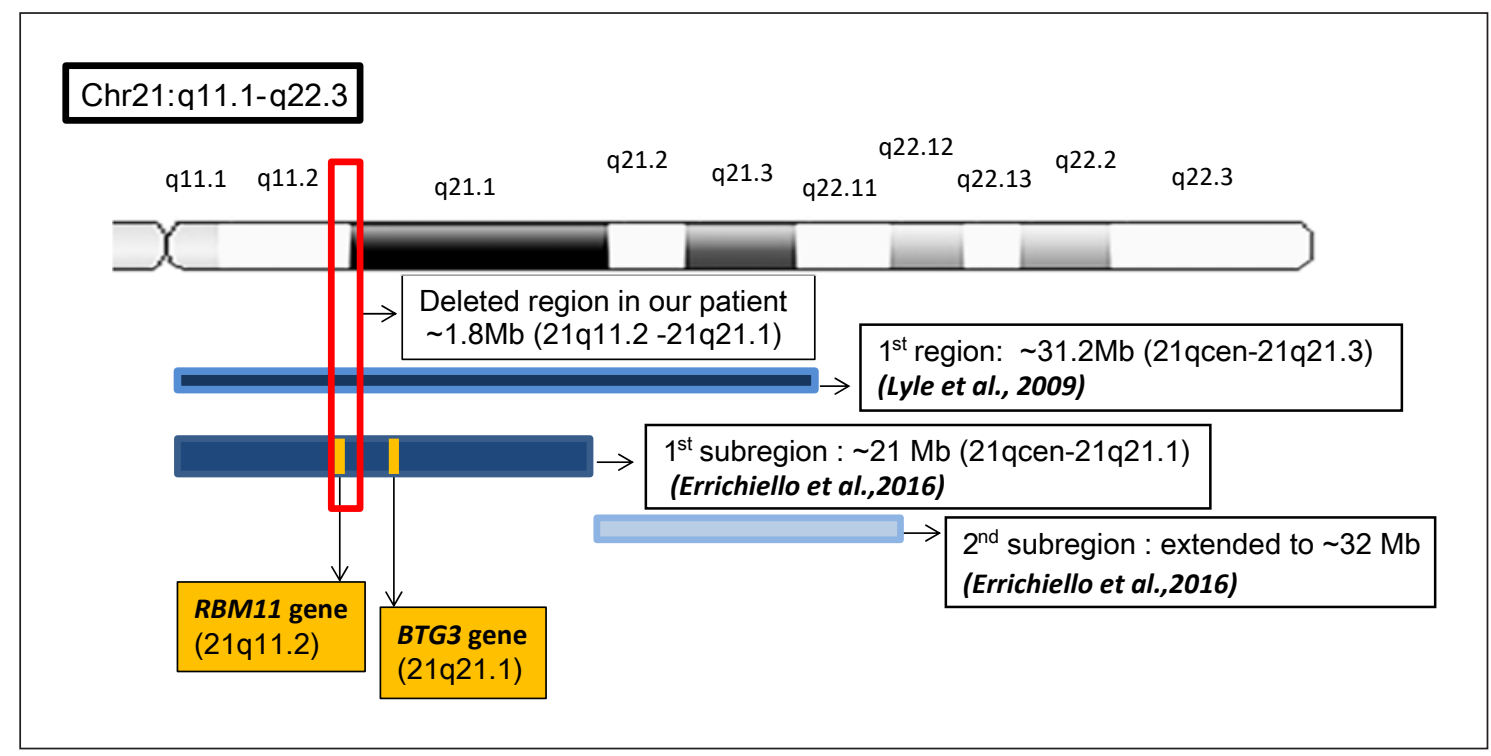

Fig. 4. Diagram representing the deleted region of our patient in chromosome $21 \mathrm{q}$ in correlation to the first region and first subregion described by Lyle et al. [2009] and Errichiello et al. [2016], respectively. Both BTG3 and $R B M 11$ are suggested to cause intellectual disability in patients located in the first subregion. . Our patient (chr21:15485008-17360796) showed deletion for the RBM11 gene (chr21:15588466-15600693) only, while BTG3 (chr21:18965968-18968526) was preserved.

of Genomic Variants (DGV), and are all found to be present in normal controls. As DGV includes a large number of differently positioned deletions, this opposes the suggested pathogenic effect of PRDM16 haploinsufficiency. However, Arndt et al. [2014] subsequently reported that there are numerous potential mechanisms, including multigene effects, long-range regulatory effects, undetected rearrangements, and position effects that might unravel an explanation for these results.

Regarding the deletion size in 1p36 region, Gajecka et al. [2007] dismissed a correlation between the size of the deletion and the clinical aspect. They emphasized that even with small deletions less than $3 \mathrm{Mb}$, the patient may present with the classical clinical phenotype of the syndrome. This assumption could also be confirmed in our patient where the deletion size is about $2.4 \mathrm{Mb}$ and the patient is presenting with multiple clinical features demonstrating monosomy 1 p36 syndrome.

Õiglane-Shlik et al. [2014] stated that the final aspect of the syndrome is ruled by more complex causes than simple contiguous gene deletion, including the effect of the position of one or more genes, environmental factors, and/or other genetic mutations that may exaggerate or alleviate the phenotype. Furthermore, Rocha et al. [2016] mentioned that epigenetic factors could alter the clinical features and preclude accurate phenotype-genotype correlation.
Relatively few cases of 1 p36 deletion syndrome due to unbalanced translocations have been reported so far (Table 3). Torisu et al. [2004] studied a female patient presenting with features suggestive of Angelman syndrome. However, the patient showed distinct dysmorphic facial features compatible with monosomy $1 \mathrm{p} 36$ syndrome. Cytogenetic studies revealed monosomy of both $1 \mathrm{p} 36.3$ and $15 \mathrm{q} 13$ in the patient. Thus, these vague manifestations that were not characterizing Angelman syndrome are possibly the outcome of haploinsufficiency of the genes included in the deleted $1 \mathrm{p} 36$ region.

Saito et al. [2011] reported a 3-month-old infant presenting with distinctive features, partial seizures, and infantile spasms associated with bilateral perisylvian polymicrogyria. Although uncommon, polymicrogyria and infantile spasms have been previously described in patients with monosomy 1p36 syndrome [Gajecka et al., 2006; Greco et al., 2018]. The patient's karyotype revealed an unbalanced translocation 46,XY,der(1)t(1;4) (p36.23;q35). Saito et al. [2011] suggested the presence of genetic loci for polymicrogyria and infantile spasms in the 1 p36 region and did not attribute any clinical findings to the translocation.

Shimada et al. [2015] described 7 patients with 1p36 deletion syndrome due to unbalanced translocations. One of them (case 20) carried an unbalanced translocation of chro- 
mosome 1 with chromosome 13 in addition to $13 \mathrm{q}$ duplication. This patient showed hypoplasia of the left ventricle which has been described to be associated with $13 \mathrm{q}$ duplication [Chen et al., 2005]. Another patient (case 34) presented with Chiari malformation type II and revealed an unbalanced translocation of chromosomes 1 and 4 as well as $4 \mathrm{p}$ duplication. This rare clinical finding was ascribed to the partial trisomy of chromosome 4 . The remaining patients in their study did not show manifestations other than those characterizing monosomy $1 \mathrm{p} 36$ syndrome.

In our patient, we encountered partial monosomy $21 \mathrm{q}$ in addition to monosomy $1 \mathrm{p} 36$ as a result of unbalanced translocation. Chromosomal microarray depicted a deletion in chromosome 21 of about $1.8 \mathrm{Mb}$ comprising bands q11.2 to q21.1. This haploinsufficiency spans numerous genes, including LIPI, LPDL, PRED5, RBM11, ABCC13, STCH, SAMSN1, HACS1, NRIP1, RIP140, CAKUT3, and USH1E.

Partial deletion of chromosome 21q (partial 21q monosomy) is a very rare condition (less than 1 per $1,000,000)$ [Errichiello et al., 2016] that has diverse clinical presentations including intellectual disability, craniofacial dysmorphism, psychological problems, developmental delay, seizures, and structural cardiac abnormalities based on the size and position of the deleted region [Roberson et al., 2011].

Lyle et al. [2009] studied 11 cases of partial 21q monosomy and categorized the deletions in $21 \mathrm{q}$ into 3 regions according to the clinical severity. They considered the first region from the centromere to about $31.2 \mathrm{Mb}$, the second region from approximately 31.2 to $36 \mathrm{Mb}$, and the third region from 36 to $37.5 \mathrm{Mb}$ to the telomere, with the first region representing the severe phenotype. In accordance with this classification, our patient harbors a $21 \mathrm{q}$ deletion located in the first region, manifesting a severe phenotype (Fig. 4).

In 3 cases from Lyle et al. [2009] (cases 31, 32, 33), the deletions were located in the first region, overlapping with that in our patient. The 3 cases presented with intellectual disability comparable to our patient. Detailed clinical data have been reported only for cases 31 and 32; these share dysmorphic features with our patient in the form of short neck, downslanting palpebral fissures, broad nasal bridge, low-set ears, in addition to low hair line in case 32. Regarding neurological abnormalities, our patient showed hypotonia similar to case 32 .

Roberson et al. [2011] postulated that the clinical severity of the cases delineated in the first region could be attributed to other chromosomal copy number variations in addition to chromosome 21 and not solely to deletions

Monosomy 1p36 Syndrome due to

Unbalanced Translocation confined to this region particularly. Our study is also in agreement with this explanation as our patient revealed an unbalanced translocation that encompasses microdeletions in both chromosome 1 and 21 and presented with a severe phenotype.

Subsequently, Errichiello et al. [2016] studied 5 cases with partial 21q monosomy and divided region 1 previously described by Lyle et al. [2009] into 2 smaller regions. They reported that subregion 1 is confined to deletions from the centromere to about $21 \mathrm{Mb}$ (21q21.1), and subregion 2 extends to $32 \mathrm{Mb}$ (21q22.11). Analogous to cases 4 and 5 in this study, our patient's deletion is located in subregion 1 (Fig. 4).

Subregion 1 includes RBM11 (OMIM *617937) and BTG3 (OMIM *605674), genes which are expressed in the central nervous system [Errichiello et al., 2016]. RBM11 is a tissue-specific regulator of splicing that could be engaged in the process of alternative splicing during nerve cell differentiation [Pedrotti et al., 2012]. BTG3 is involved in neurogenesis in the central nervous system, as it has a role in regulation of cellular proliferation and apoptosis [Ren et al., 2015]. Errichiello et al. [2016] correlated the phenotypic severity, mainly intellectual disability, of the cases located in subregion 1 with the haploinsufficieny of these 2 genes.

Although the BTG3 gene (chr21:18965968-18968526) is conserved in our patient, RBM11 (chr21:1558846615600693) has been deleted. Hence, we assume that haploinsufficiency of RBM11 may have an impact on our patient's phenotype, and we propose that the existence of intellectual disability in our patient is a result of haploinsufficiency of multiple genes including SKI and GNB1 at chromosome 1 and RBM11 at chromosome 21.

\section{Conclusion}

In the current study, we have analyzed the clinical and cytogenetic data of a female patient presenting with manifestations of 1 p36 deletion syndrome. Phenotype-genotype correlation for monosomy $1 \mathrm{p} 36$ could be performed for the core clinical features of the syndrome. Nevertheless, the final aspect of the syndrome depends on complex factors rather than a simple contiguous gene deletion. Position effect, associated copy number changes or other genetic abnormalities and epigenetic factors all can exaggerate or alleviate the phenotype.

The unbalanced translocation between chromosome 1 and 21 in our patient could be an aggravating factor for the phenotypic severity, in particular intellectual disability, as a 
result of copy number variances involving both chromosomes. Monosomy 1p36 syndrome due to unbalanced translocation can present either with the classical picture of the syndrome or with additional phenotype according to the disrupted genes in the other involved chromosome.

\section{Acknowledgement}

The authors are grateful to the patient and her parents for participating in this study.

\section{Statement of Ethics}

The study was conducted according to the guidelines of the Medical Research Ethics Committee of the National Research Centre based on the World Medical Association Declaration of Helsinki. Informed consent was obtained from the patient's guardians.

\section{Conflict of Interest Statement}

The authors have no conflicts of interest to declare.

\section{Funding Sources}

No funding was obtained for this study.

\section{Authors' Contributions}

All authors have made substantial contributions to the conception of the work, analysis, and interpretation of data, participated in revising the work, are responsible for all aspects of the work in ensuring that questions related to the accuracy of the work are appropriately investigated, and they all approved the final version to be published.

\section{References}

Arndt AK, Schafer S, Drenckhahn JD, Sabeh MK, Plovie ER, Caliebe A, et al. Fine mapping of the 1 p36 deletion syndrome identifies mutation of PRDM16 as a cause of cardiomyopathy. Am J Hum Genet. 2013;93(1):67-77.

Arndt AK, Macrae CA, Klaassen S. Reponse to De Leeuw and Houge. Am J Hum Genet. 2014; 94(1):154-5.

Bahi-Buisson N, Guttierrez-Delicado E, Soufflet C, Rio M, Daire VC, Lacombe D, et al. Spectrum of epilepsy in terminal 1p36 deletion syndrome. Epilepsia. 2008;49(3):509-15.

Ballif BC, Yu W, Shaw CA, Kashork CD, Shaffer LG. Monosomy 1p36 breakpoint junctions suggest pre-meiotic breakage-fusion-bridge cycles are involved in generating terminal deletions. Hum Mol Genet. 2003;12(17):215365.

Battaglia A, Hoyme HE, Dallapiccola B, Zackai E, Hudgins L, McDonald-McGinn D, et al. Further delineation of deletion 1p36 syndrome in 60 patients: a recognizable phenotype and common cause of developmental delay and mental retardation. Pediatrics. 2008;121(2): 404-10.

Chen CP, Chern SR, Hsu CY, Lee CC, Lee MS Wang W. Prenatal diagnosis of de novo partial trisomy 13q (13q22 --> qter) and partial monosomy 8p (8p23.3 --> pter) associated with holoprosencephaly, premaxillary agenesis, hexadactyly, and a hypoplastic left heart. Prenat Diagn. 2005;25(4):334-6.

De Leeuw N, Houge G. Loss of PRDM16 is unlikely to cause cardiomyopathy in 1 p36 deletion syndrome. Am J Hum Genet. 2014;94(1): 153-4.

Errichiello E, Novara F, Cremante A, Verri A, Galli J, Fazzi E, et al. Dissection of partial 21c monosomy in different phenotypes: clinical and molecular characterization of five cases and review of the literature. Mol Cytogenet. 2016;9(1):21.

Firth HV, Richards SM, Bevan AP, Clayton S, Corpas M, Rajan D, et al. DECIPHER: Database of Chromosomal Imbalance and Phenotype in Humans Using Ensembl Resources. Am J Hum Genet. 2009;84(4):52433.

Gajecka M, Yu W, Ballif BC, Glotzbach CD, Bailey KA, Shaw CA, et al. Delineation of mechanisms and regions of dosage imbalance in complex rearrangements of $1 \mathrm{p} 36$ leads to a putative gene for regulation of cranial suture closure. Eur J Hum Genet. 2005;13(2):13949.

Gajecka M, Glotzbach CD, Jarmuz M, Ballif BC, Shaffer LG. Identification of cryptic imbalance in phenotypically normal and abnormal translocation carriers. Eur J Hum Genet. 2006;14(12):1255-62.

Gajecka M, Mackay KL, Shaffer LG. Monosomy 1 p36 deletion syndrome. Am J Med Genet C Semin Med Genet. 2007;145C(4):346-56.

Greco M, Ferrara P, Farello G, Striano P, Verrotti A. Electroclinical features of epilepsy associated with 1 p36 deletion syndrome: a review. Epilepsy Res. 2018;139:92-101.

Heilstedt HA, Ballif BC, Howard LA, Kashork CD, Shaffer LG. Population data suggest that deletions of 1 p36 are a relatively common chromosome abnormality. Clin Genet. 2003a; 64(4):310-6.

Heilstedt HA, Ballif BC, Howard LA, Lewis RA, Stal S, Kashork CD, et al. Physical map of 1p36, placement of breakpoints in monosomy $1 \mathrm{p} 36$, and clinical characterization of the syndrome. Am J Hum Genet. 2003b;72(5):120012.
Hiraki Y, Fujita H, Yamamori S, Ohashi H, Eguchi M, Harada N, et al. Mild craniosynostosis with 1 p36.3 trisomy and 1p36.3 deletion syndrome caused by familial translocation $\mathrm{t}(\mathrm{Y} ; 1)$. Am J Med Genet A. 2006;140(16):1773-7.

ISCN 2016. An International System for Human Cytogenomic Nomenclature. McGowan-Jordan J, Simons A, Schmid M (eds). Cytogenet Genome Res. 2016;149(1-2):1-140.

Jordan VK, Zaveri HP, Scott DA. 1p36 deletion syndrome: an update. Appl Clin Genet. 2015; 8:189-200.

Lyle R, Béna F, Gagos S, Gehrig C, Lopez G, Schinzel A, et al. Genotype-phenotype correlations in Down syndrome identified by array CGH in 30 cases of partial trisomy and partial monosomy chromosome 21. Eur J Hum Genet. 2009;17(4):454-66

Õiglane-Shlik E, Puusepp S, Talvik I, Vaher U, Rein R, Tammur P, et al. Monosomy 1p36 - a multifaceted and still enigmatic syndrome: four clinically diverse cases with shared white matter abnormalities. Eur J Paediatr Neurol. 2014;18(3):338-46.

Pedrotti S, Busà R, Compagnucci $\mathrm{C}$, Sette $\mathrm{C}$. The RNA recognition motif protein RBM11 is a novel tissue-specific splicing regulator. $\mathrm{Nu}$ cleic Acids Res. 2012;40(3):1021-32.

Pinkel D, Gray J, Trask B, van den Engh G, Fuscoe J, van Dekken H. Cytogenetic analysis by in situ hybridization with fluorescently labeled nucleic acid probes. Cold Spring Harb Symp Quant Biol. 1986;51:151-157.

Ren XL, Zhu XH, Li XM, Li YL, Wang JM, Wu PX, et al. Down-regulation of BTG3 promotes cell proliferation, migration and invasion and predicts survival in gastric cancer. J Cancer Res Clin Oncol. 2015;141(3):397405 
Roberson ED, Wohler ES, Hoover-Fong JE, Lisi E, Stevens EL, Thomas GH, et al. Genomic analysis of partial 21q monosomies with variable phenotypes. Eur J Hum Genet. 2011; 19(2):235-8.

Rocha CF, Vasques RB, Santos SR, Paiva CL. Mini-Review: Monosomy 1p36 syndrome: reviewing the correlation between deletion sizes and phenotypes. Genet Mol Res. 2016; 15(1):10.4238/gmr.15017942.

Rosenfeld JA, Crolla JA, Tomkins S, Bader P, Morrow B, Gorski J, et al. Refinement of causative genes in monosomy 1 p36 through clinical and molecular cytogenetic characterization of small interstitial deletions. Am J Med Genet A. 2010;152A(8):1951-9.

Saito Y, Kubota M, Kurosawa K, Ichihashi I, Kaneko Y, Hattori A, et al. Polymicrogyria and infantile spasms in a patient with $1 \mathrm{p} 36$ deletion syndrome. Brain Dev. 2011;33(5): 437-41.

Seo GH, Kim JH, Cho JH, Kim GH, Seo EJ, Lee $\mathrm{BH}$, et al. Identification of $1 \mathrm{p} 36$ deletion syndrome in patients with facial dysmorphism and developmental delay. Korean J Pediatr. 2016;59(1):16-23.

Shaffer LG, Lupski JR. Molecular mechanisms for constitutional chromosomal rearrangements in humans. Annu Rev Genet. 2000;34:297329.
Shapira SK, McCaskill C, Northrup H, Spikes AS, Elder FF, Sutton VR, et al. Chromosome 1p36 deletions: the clinical phenotype and molecular characterization of a common newly delineated syndrome. Am J Hum Genet. 1997; 61(3):642-50.

Shimada S, Shimojima K, Okamoto N, Sangu N, Hirasawa K, Matsuo M, et al. Microarray analysis of 50 patients reveals the critical chromosomal regions responsible for $1 \mathrm{p} 36$ deletion syndrome-related complications. Brain Dev. 2015;37(5):515-26.

Temtamy SA, Abd El-Ghani HM, Shehab MI, Aglan MS, Samy RM, Abd El-Rahmen MA, et al. Detection of 1 (p36) deletion in patients with developmental delay and facial dysmorphism. Res J Med Med. Sci. 2011;6(1):35-42.

Torisu H, Yamamoto T, Fujiwaki T, Kadota M, Oshimura M, Kurosawa K, et al. Girl with monosomy 1p36 and Angelman syndrome due to unbalanced der(1) transmission of a maternal translocation $\mathrm{t}(1 ; 15)(\mathrm{p} 36.3 ; \mathrm{q} 13.1)$. Am J Med Genet A. 2004;131(1):94-8.

Verma RS, Babu A. Human Chromosomes: A Manual of Basic Techniques. New York: McGraw-Hill; 1995.
Vigdorovich N, Ben-Sira L, Blumkin L, Precel R, Nezer I, Yosovich K, et al. Brain white matter abnormalities associated with copy number variants. Am J Med Genet. 2020;182(1):93103.

Watanabe M, Hayabuchi Y, Ono A, Naruto T, Horikawa H, Kohmoto T, et al. Detection of 1 p36 deletion by clinical exome-first diagnostic approach. Hum Genome Var. 2016;3: 16006.

Windpassinger C, Kroisel PM, Wagner K, Petek E. The human gamma-aminobutyric acid A receptor delta (GABRD) gene: molecular characterisation and tissue-specific expression. Gene. 2002;292(1-2):25-31.

Zaveri HP, Beck TF, Hernández-García A, Shelly KE, Montgomery T, van Haeringen A, et al. Identification of critical regions and candidate genes for cardiovascular malformations and cardiomyopathy associated with deletions of chromosome 1p36. PLoS One. 2014; 9(1):e85600.

Zhang X, Zhu J, Yang GY, Wang QJ, Qian L, Chen YM, et al. Dishevelled promotes axon differentiation by regulating atypical protein kinase C. Nat Cell Biol. 2007;9(7):743-54. 